УДК 338.246

Коновалова Л.К., Окорков В.В.

ФГБНУ «Верхневолжский Федеральный аграрный научный центр», Суздаль, e-mail: mail@vnish.org

\title{
СИСТЕМА УПРАВЛЕНИЯ ТЕХНОЛОГИЯМИ В АСПЕКТЕ ЕЕ ДВИЖУЩИХ СИЛ
}

Ключевые слова: система управления технологиями, региональный уровень, уровень хозяйствующего субъекта, инновационно-инвестиционный процесс, движущие силы, экономическое стимулирование товаропроизводителей, материальное стимулирование персонала, заинтересованность и ответственность.

В статье (шифр научной специальности 08.00.05) рассмотрена экономическая категория «управление технологиями» с точки зрения актуальности, сущности, содержания, уровней осуществления и т.д. Акцент сделан на позиции «движущие силы», в качестве которых рассматриваются экономическое стимулирование сельхозпроизводителей и материальное стимулирование персонала, построенные на принципах заинтересованности и ответственности. На основании результатов исследования сформулированы деловые предложения для сельхозпроизводителей и региональных органов управления сельским хозяйством Владимирской области. Основные из них следующие: 1) выбрать на региональном уровне 5-6 «пилотных» предприятий (сельхозорганизаций) для внедрения интенсивных агротехнологий при сотрудничестве с научными учреждениями; 2) предложено совершенствование господдержки таких предприятий (в рамках «зеленой» корзины) на срок не менее 4-х лет, а именно, величину субсидии на оказание несвязанной поддержки в области растениеводства повысить в размере, пропорциональном соотношению затрат на интенсивные и экстенсивные технологии; 3) предложен перечень критериев для оценки уровня культуры земледелия; 4) предложены критерии для установлении мер заинтересованности и ответственности за результаты процесса управления технологиями на различных уровнях управления в крупном предприятии.

Konovalova L.K., Okorkov V.V.

Upper Volga Federal Agrarian Research Center, Suzdal, e-mail: mail@vnish.org

\section{TECHNOLOGY MANAGEMENT SISTEM IN THE ASPECT OF IT'S DRIVING FORCES}

Keywords: technology management system, regional level, level of economic subject, innovative and investment process; driving forces; economic stimulation of commodity producers; material (monetary) stimulation of personal; interest and responsibility.

In article (science specialization code is 08.00 .05 ) has described economic category "technology management" from point of view actuality, essence, content, levels of implementation and so on. Accent has done on position "driving forces", which are considered as economic stimulation of agricultural producers and material (monetary) stimulation of personal, building on interest and responsibility principles. In basis of investigation results had formulated business proposals for agricultural producers and regional management establishments at agriculture in Vladimir region. The key ones are following: 1) at regional level it should celebrate $5-6$ organizations - technology leaders - for adaptation intensive technology at a collaboration with science establishments; 2) it has offered the improvement of state support to these enterprises (within "grin" basket) during period no less than 4 yeas - size of subsidy on not related support at plant growing branch should increase as proportion between expenses on intensive technology and extensive ones; 3) the row of criteria for estimation of culture land husbandry level has offered; 4) the row of criteria for setting of interest and responsibility measures for results of technology management processes on different levels of management at the large enterprise.

\section{Введение}

Актуальность данной темы связана с принятой в стране стратегией перехода российской экономики от экспортносырьевой модели к неоиндустриальной, где определяющим направлением является прорыв в технологическом развитии производства. В условиях накала конкуренции национальных экономик на международном уровне Россия «демонстрирует» значительное отставание от развитых стран. Для справки: в промышленности США в середине первого десятилетия XXI века насчитывалось около 6,5 млрд. машинных работников, из них 15\% автоматизированных; в Рос- 
сии - 2,3 млрд. машинных работников, из них автоматизированных - только $2 \%$ [1]. С другой стороны, по данным крупнейшей международной консалтинговой компании «Price water house Coopers», относительно прогноза мирового развития с настоящего времени по 2050 год, у России имеется потенциал для того, чтобы стать крупнейшей экономикой в Европе [2]. Для упорядочения указанного инновационного процесса в стране должна быть создана единая система управления технологиями по уровням государственного и муниципального управления, включая уровень хозяйствующего субъекта. В этом смысле важно определить движущие силы, под которыми понимаются те позиции системы, задействуя которые мы «запускаем» весь ее механизм.

Цели исследования:

1) уточнение сущности и содержания категории «управление технологиями»;

2) характеристика движущих сил системы на примере аграрного производства;

3) предложения по реализации движущих сил системы управления агротехнологиями во Владимирской области в среднесрочной перспективе.

\section{Материал и методы исследования}

В работе использованы методы, присущие как исследованиям теоретического характера (абстрактно-логический, структурного анализа, индукции, дедукции, системный подход, ситуационный подход), так и методы конкретно-экономических исследований (монографический, сравнительного анализа, графический, метод учета затрат и калькулирования себестоимости «Директ-костинг» [3]).

\section{Результаты исследований и их обсуждение}

\section{Уточнение сущиости и содержания категории «управление технологиями»}

В предыдущих статьях на данную тему авторами была разработана теоретическая структурная схема реализации экономической категории «управление технологиями» [4]. Здесь она приводится в уточненном виде - добавлены следующие структурные элементы: класси- фикация технологий; принцип адаптивности к условиям объекта; движущие силы; в перечень уровней реализации добавлен уровень федерального округа (рисунок 1). Схему следует «читать» по вертикали и по горизонтали. Вертикальная составляющая обозначена уровнями управления, горизонтальная этапами функционирования на каждом уровне: целеполагание; направляющая функция (сущность); ориентирующая, координирующая и регулирующая функции (принципы); стимулирующая функция (движущие силы); учет и контроль, оценка эффективности.

Для удобства восприятия читателями сущности термина «управление технологиями» переведем это определение в плоскость ответа на вопрос: «Чем отличаются функции технолога от функций менеджера технологий?» Ответ, по-видимому, можно сформулировать так: инженер-технолог, как правило, занят разработкой конкретного технологического процесса для определенной стадии цикла производства, конкретного объекта. В то же время в поле зрения менеджера технологий находится весь жизненный цикл производства и реализации всех товаров, выпускаемых предприятием, и даже целый комплекс жизненных циклов технологий. Его главное предназначение состоит в том, чтобы «запускать» и контролировать «оборот» комплекса взаимосвязанных технологий, как системы; искать новые, более эффективные технологии; своевременно менять старые технологии на новые.

\section{Характеристика двиюущцх сил системы управления технологиями}

В качестве «маховика», запускающего и поддерживающего процесс управления технологиями (движущих сил), на региональном уровне и уровне хозяйствующего субъекта, на наш взгляд, можно назвать комплекс мероприятий по экономическому стимулированию сельхозпроизводителей и материальному стимулированию персонала, занятого в сельхозорганизациях, а также в органах региональной власти и местного самоуправления. Эти меры должны разрабатываться на основе отношений заинтересованности и ответственности. 


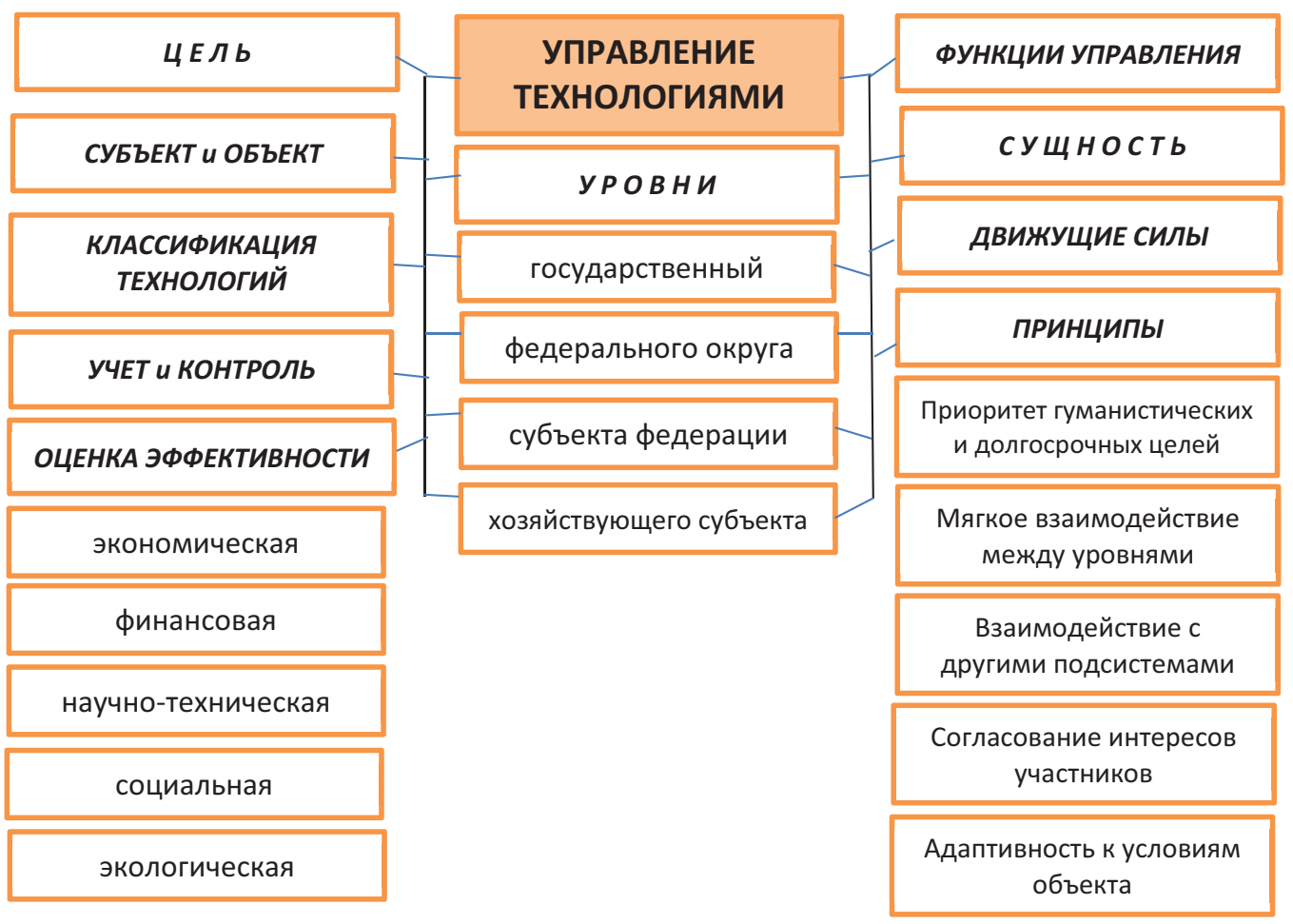

Рис. 1. Теоретическая структурная схема реализации категории «управление технологиями»

\section{Реализачия отночения заинтересованности}

Под экономическим стимулированием в отношении сельхозтоваропроизводителя мы понимаем, в частности, льготное налогообложение и усиленное адресное государственное субсидирование производства в предприятиях, применяющих интенсивные и (или) ресурсосберегающие технологии. Целесообразно во Владимирской области выбрать 5-6 т.н. пилотных предприятий для внедрения в них на научной основе интенсивных технологий в растениеводстве. При этом для них размер государственной субсидии на оказание несвязанной поддержки в области растениеводства следовало бы повысить, на наш взгляд, не менее, чем на 4-летний период в размере, пропорциональном соотношению затрат на интенсивные и экстенсивные технологии ${ }^{1}$, т.е. при-

${ }^{1}$ Сейчас во Владимирской области федеральная субсидия на оказание несвязанной поддержки в области растениеводства составляет 279 руб./га; единая региональная субсидия (на закупку семян высоких репродукций) 520 руб./га (по зерновым) и 1800 руб./га (по бобовым травам). мерно в 2,5 раза. По нашему мнению, предложенные меры не противоречат требованиям ВТО, ограничивающим меры господдержки рамками «зеленой корзины» [5].

Подбор «пилотных» предприятий предлагаем осуществлять по детализированному критерию, который можно обозначить как «высокая культура земледелия». Дело в том, что согласно классификации агротехнологий по уровню интенсификации производства [6] последняя является одним из основных условий применения интенсивных технологий. Для выбора предприятий, которые подходили бы для внедрения интенсивных технологий, биологического и точного земледелия следует установить конкретные численные нормативы, согласно которым можно определить, соответствует ли хозяйственная деятельность предприятия вышеназванному интегральному показателю «высокая культура земледелия». На наш взгляд, для этой цели могут применяться следующие критерии оценки. Просматриваются 3 группы показателей. 1-я группа касается плодородия и фитосанитарного состояния почвы: содержание гумуса 
в почве - не ниже норматива, положительный его баланс в течение 3-х лет по всем полям севооборотов; содержание подвижного фосфора и обменного калия - не ниже норматива [7]; содержание нитратов и пестицидов - не выше нормы; засоренность корневищевыми и корнеотпрысковыми сорняками должна практически отсутствовать, могут допускаться, на наш взгляд, лишь незначительные «забегания» их с обочин полей; засоренность однолетними сорняками - в пределах нормы; недопущение роста необрабатываемых площадей. Во 2-ю группу могут войти показатели, характеризующие уровень продуктивности земли: рост урожайности в течение 5-ти лет ${ }^{2}$ или производство основных товарных видов продукции растениеводства и животноводства в расчете на 100 га пашни [8], показатели качества сельхозпродукции. К 3-й группе можно отнести показатели, характеризующие создание базы для стабильного развития предприятия в перспективе: рост технического и инновационного потенциала, проведение активной работы по укреплению «человеческого потенциала».

По предварительным оценкам технологическими лидерами по природно-хозяйственным зонам могут быть следующие сельхозорганизации.

В зоне Ополье (производство зерна и молока, серые лесные почвы): СПК «Спасское», СПК «Гавриловское» Суздальского района, ООО «Шихобалово» Юрьев-Польского р-на; в Северо-восточной зоне (производство зерна и молока, дерново-подзолистые супесчаные почвы): АО ПЗ «Илькино», СПК «Дмитриевы горы» Меленковского р-на; в Южной зоне - Мещере - (благоприятные условия для возделывания картофеля): ООО «Рождество» Петушинского р-на.

Считаем, что остальные сельхозорганизации в области будут применять нормальные технологии, применение экстенсивных технологий, снижающих плодородие почв, в нашем представлении, полностью исключается. Вместе с тем, в хозяйствах, применяющих нормальные технологии, также должно проводиться постепенное технологиче-

\footnotetext{
${ }^{2}$ Определенный при нивелировании влияния погодных условий с помощью экономикостатистических методов.
}

ское усовершенствование. Здесь на первый план выступает материальное стимулирование персонала. Например, можно установить стимулирующую надбавку механизаторам, работающим на современной технике, а также единовременную доплату за рационализаторские предложения, доплату за качество работ и соблюдение технологической дисциплины.

Не стоит сбрасывать со счетов несправедливо забытую систему оплаты труда (в различных ее модификациях) за конечные результаты или с учетом конечных результатов, так как, заботясь о производстве большего количества продукции лучшего качества и об экономии производственных затрат, непосредственные исполнители работ будут заинтересованы не только в соблюдении технологической дисциплины, но и во введении усовершенствований в технологический процесс по согласованию с ответственными за последний лицами.

Что касается менеджера технологий, по этой должности эффективным может оказаться установление зависимости переменной части текущей оплаты труда от дохода предприятия в целом, а также разовой доплаты за каждое эффективное технологическое нововведение.

\section{Реализация отношения ответственности}

Из двух принципов - заинтересованность и ответственность - второй является в меньшей степени разработанным в литературе, хотя эти принципы не могут в полной мере быть реализованы друг без друга.

Ранее нами рассмотрены возможные варианты установления мер ответственности трудовых коллективов и работников за производственные и «затратные» показатели на примере предприятия интегративного типа [9]. В этой статье остановимся на критериях технологической ответственности. Разработка проблемы проводится по ступеням иерархии управления: работник - звено бригада - производственный комплекс 1-го или 2-го типа ${ }^{3}$ - предприятие в це-

3 Производственный комплекс 1-го типа действует на принципах внутрихозяйственного хозрасчета, 2-го типа - как предпринимательская единица. 
лом. Подразумевается, что обособление производственных участков по уровням происходит, по преимуществу, на основе технологической автономизации.

Первая ступень - работник. В отношении работника действует двойная ответственность: 1) перед коллективом подразделения и 2) непосредственно перед менеджером технологий, как представителем работодателя. В первом случае решением органа управления первичным трудовым коллективом (звеном, бригадой) работнику может быть снижен коэффициент трудового участия (КТУ) за нарушение технологической дисциплины, что уменьшит его долю в коллективном фонде оплаты труда (фонде премирования). При втором направлении ответственности менеджер технологий вправе при выполнении работником определенного вида работы с нарушением технологических требований или просто не качественно составить акт о допущении брака в работе и применить меры ответственности в отношении работника согласно Трудовому Кодексу РФ (ст. 156) [10]. Кроме того, может быть поставлен вопрос о причинении ущерба работодателю из-за нарушения технологических параметров на участке производства, контролируемом конкретным работником. Согласно ТК РФ работник обязан возместить работодателю причиненный ему прямой действительный ущерб. Однако недополученные доходы (упущенная выгода) взысканию с работника не подлежат. Под прямым действительным ущербом понимается реальное уменьшение наличного имущества работодателя или ухудшение состояния указанного имущества, а также необходимость для работодателя произвести затраты на приобретение или восстановление имущества (ст. 238 ТК РФ). Для справки: статьей 241 ТК РФ предусмотрены пределы материальной ответственности работника - средний месячный заработок. В этом смысле задача менеджера технологий состоит в следующем: организовать комиссию, провести своеобразное расследование, в результате которого установить факт брака или (и) ущерба, размер ущерба, а также степень вины работника, оформить документально. Только после этого сумма ущер- ба, нанесенного работником, взимается с него полностью или частично.

Приведем пример. Тракторист-машинист произвел посев яровой зерновой культуры с нарушением технологии. В результате мы имеем изреженные всходы. После проведения соответствующих вышеуказанных процедур в отношении работника должно поступить распоряжение о пересеве участков с изреженными всходами, и эта работа не будет оплачена. Кроме того, опятьтаки, после проведения необходимых по установленной процедуре мероприятий, может быть рассчитан размер прямого действительного ущерба, в данном случае, по-видимому, только в размере дополнительной потребности в семенах и топливно-смазочных материалах на переделку работы, так как основные средства работодателя (земля и техника) не пострадали.

Следующая ступень - звено. Коллектив звена, как и на предыдущей ступени, несет ответственность за беспрекословное, точное соблюдение технологических требований. При нарушении технологии производства может быть уменьшена доля звена в коллективном фонде оплаты труда бригады (фонде премирования)

Что касается следующей ступени управления - бригады, то ее коллективу может предоставляться определенная самостоятельность ${ }^{4}$ в выполнении плановых заданий, кроме того, могут применяться элементы хозрасчета. Ответственность за соблюдение технологии осуществляется в двух направлениях: 1) ответственность перед производственным комплексом, как непосредственной вышестоящей инстанцией и 2) перед предприятием. С целью реализации пункта 1) в наказание за нарушение технологических требований можно снизить долю бригады в распределяемой части хозрасчетного дохода производственного комплекса 1 типа или в распределяемой части прибыли производственного комплекса 2 типа (в фонде потребления). При этом важно, чтобы бригада, в которой были нарушены некоторые технологические

${ }^{4}$ Функции, которые коллектив бригады может выполнять самостоятельно, показаны в источнике 9 . 
параметры, не испытывала сложности с участием в использовании других фондов, создаваемых на уровне комплекса, особенно фонда развития производства. Для реализации пункта 2) могут применяться штрафные выплаты из коллективного фонда оплаты труда бригады (фонда премирования) в пользу предприятия. Данная мера может не применяться, если бригадир выполнит свои обязанности по выявлению причин нарушения технологии, виновных лиц, примет участие в работе специальной комиссии, оформлении соответствующих актов, и таким образом ответственность будет переадресована с бригады на конкретных лиц. При этом следует помнить, что юридически меры индивидуальной и коллективной материальной ответственности установлены в ТК РФ (ст. 238-250) лишь в случае нанесения прямого действительного ущерба. Если при нарушении технологических требований прямого действительного ущерба не выявлено, однако налицо явная недополученная выгода, указанные выше материальные претензии могут быть реализованы в рамках предприятия на основе заключенных внутрихозяйственных договоров подряда, трудовых и коллективных договоров, др. локальных нормативных актов. В любом случае речь не идет о лишении работника части уже начисленной заработной платы.

Переходим по таблице к более высокой иерархической ступени управления - производственному комплексу 1 типа. Этот тип подразделения основан на внутрихозяйственном хозрасчете. Коллективу такого подразделения предоставляется реальная самостоятельность ${ }^{5}$ в выполнении плановых заданий, устанавливается ответственность перед предприятием за объемы производства продукции и коммерческий результат. В соответствии с достаточно высоким уровнем хозяйственной самостоятельности и экономической ответственности в отношении такого подразделения, по-видимому, не следует устанавливать жесткие меры ответственности за неукоснительное соблюдение всех технологических параметров. Очевид-

\footnotetext{
5 Функции, выполняемые самостоятельно в подразделении хозрасчетного типа, показаны в источнике [9].
}

но, подойдет требование о соблюдении принятой на предприятии технологии лишь в принципе, при этом работники коллектива могут самостоятельно вводить технологические приемы совершенствующего типа, не производя радикальных технологических изменений. В случае, если технология существенно нарушена, можно установить ответственность в виде уменьшения суммы хозрасчетного дохода, направляемой на потребление, при этом, не затрагивая другую часть дохода, направляемую на развитие производства (инновации, модернизацию оборудования и т.п.).

Вместо комплексов хозрасчетного типа в крупном предприятии могут создаваться производственные комплексы 2 типа, то есть предпринимательские единицы. Такой производственный комплекс принимает статус самостоятельного первичного предприятия, а само крупное предприятие принимает экономическую форму предприятия интегративного типа, что соответствует таким организационно-правовым формам, как, например, ассоциация, агрофирма или холдинг.

Подавляющее большинство функций первичное предприятие выполняет самостоятельно, вплоть до выбора видов продукции для производства, организации финансовой деятельности, ответственности перед государственным и муниципальным бюджетом (налоги). При этом ассоциации (холдингу) делегируется лишь ограниченный набор функций. Это может быть кредитование, консультирование специалистов, стратегическое планирование. Первичное предприятие не подотчетно интегративному предприятию за результаты производственно-финансовой деятельности. При наличии убытков оно может продолжать свое функционирование при условии обеспечения отчислений в пользу ассоциации.

По-видимому, перед такого рода подразделением не логично устанавливать ответственность за точное соблюдение принятых технологий. Вместо этого подойдет установление контрольных показателей, которые дадут информацию о том, что, по крайней мере, в результате предпринимательской деятельности первичных предприятий не снижен 
потенциал технологического (а также и по другим направлениям) развития интегративного предприятия в целом. В качестве контрольных показателей в сельскохозяйственном предприятии могут быть приняты критерии, которые в данной статье выше перечислены при характеристике интегрального показателя «культура земледелия». При обнаружении несоответствия вышеуказанных контрольных показателей установленным внутрихозяйственным или государственным стандартам первичному предприятию может быть представлен счет по выплате суммы расчетного ущерба, например, из-за снижения плодородия почвы или вреда, нанесенного окружающей среде. Сумма штрафа поступает в фонд развития производства (социального развития) интегративного предприятия. Вместо последней меры для сохранения единого технолого-воспроизводственного и инновационно-инвестиционного процесса можно предусмотреть заключение договоров между самими производственными комплексами, в которых заложить меры материальной ответственности за поставку продукции (услуг), несоответствующих установленным технологическим и другим стандартам.

На верхнем уровне управления предприятием технологическую ответственность несет менеджер технологий. Его основные функции описаны выше. Меры материальной ответственности в отношении менеджера технологий могут заключаться в не начислении переменной части заработной платы в ситуациях, связанных со снижением объема производства продукции (или снижением темпа его роста), с ростом энергоемкости и трудоемкости производства, снижением уровня развития производственного потенциала предприятия.

В предприятии интегративного типа набор выполняемых функций менеджера технологий значительно сокращается по сравнению с «обычным» предприятием. Главные функции: разработка долгосрочной технологической стратегии, гибкой тактики эволюционного технологического усовершенствования по этапам на основе альтернативных вариантов, план внедрения новых техно- логий с обоснованием эффективности, разработка технологических карт, решение проблем, связанных с погодным и экономическим риском, анализ результатов реализации разработанной стратегии, выявление отклонений от задуманного, формулировка предложений самостоятельным производственным комплексам по внесению изменений в технологический процесс. При этом исключаются «внедренческие» функции, а также функции тотального контроля над точным соблюдением всех технологических требований.

\section{Выводы и предложения}

По материалам исследования нами сформулированы выводы и на основании их предложения для сельхозпроизводителей и региональных и муниципальных органов управления сельским хозяйством по реализации системы управления агротехнологиями во Владимирской области в среднесрочной перспективе (таблица).

\section{Заключение}

В результате проведенного исследования получены следующие результаты.

1. Уточнены сущность и содержание экономической категории «управление технологиями». 2. Определены основные движущие силы процесса реализации вышеназванной категории 3. Сформулированы выводы и предложения для сельхозпроизводителей и региональных (муниципальных) органов управления сельским хозяйством. 4. В качестве основных предложений можно назвать определение в области т.н. пилотных предприятий по организации внедрения интенсивных технологий в растениеводстве и перечень критериев оценки уровня культуры земледелия для их отбора; разработку в отношении предприятий - технологических лидеров адресного государственного субсидирования; меры материальной заинтересованности и ответственности персонала сельхозорганизаций (и особо для крупных предприятий интегративного типа) за соблюдение технологических и агроэкологических требований в процессе управления технологиями. 
Выводы и предложения

по реализации системы управления агротехнологиями

\begin{tabular}{|c|c|c|}
\hline Выводы & Предложения & Примечание \\
\hline $\begin{array}{l}\text { 1. Целесообразно во Вла- } \\
\text { димирской области вы- } \\
\text { брать 5-6 «пилотных» } \\
\text { предприятий для внедре- } \\
\text { ния в них на научной осно- } \\
\text { ве интенсивных техноло- } \\
\text { гий в растениеводстве }\end{array}$ & $\begin{array}{l}\text { 1.Для этих предприятий предложено увеличить } \\
\text { размер госсубсидии на оказание несвязанной } \\
\text { поддержки в области растениеводства на срок не } \\
\text { менее 4-х лет в размере, пропорциональном соот- } \\
\text { ношению между затратами на экстенсивные и ин- } \\
\text { тенсивные технологии, т.е. примерно в 2,5 раза } \\
\text { 2. Предложен перечень критериев, по которым } \\
\text { можно проводить отбор предприятий - технологи- } \\
\text { ческих лидеров }\end{array}$ & $\begin{array}{l}\text { Для региональных } \\
\text { органов управле- } \\
\text { ния сельским хо- } \\
\text { зяйством }\end{array}$ \\
\hline $\begin{array}{l}2 . \text { Остальные предпри- } \\
\text { ятия должны стремиться } \\
\text { к освоению полноценных } \\
\text { технологий r нормально- } \\
\text { го уровня. Экстенсивные } \\
\text { технологии должны быть } \\
\text { постепенно полностью ис- } \\
\text { ключены как снижающие } \\
\text { почвенное плодородие }\end{array}$ & $\begin{array}{l}\text { Увеличение посевных площадей под выращивание } \\
\text { злаковых культур для производства товарного се- } \\
\text { менного зерна сортов отечественной селекции, что } \\
\text { будет соответствовать интересам как товаропроиз- } \\
\text { водителей (увеличение прибыли), так и интересам } \\
\text { государства (обеспечение продовольственной без- } \\
\text { опасности) }\end{array}$ & $\begin{array}{l}\text { Для сельхозпро- } \\
\text { изводителей }\end{array}$ \\
\hline $\begin{array}{l}\text { 3. Движущими силами } \\
\text { при реализации системы } \\
\text { управления технологиями } \\
\text { являются экономическое } \\
\text { стимулирование сельхоз- } \\
\text { производителей и матери- } \\
\text { альное стимулирование } \\
\text { персонала, построенные на } \\
\text { принципах заинтересован- } \\
\text { ности и ответственности }\end{array}$ & $\begin{array}{l}\text { 1. Меры материального стимулирования персонала } \\
\text { производственных трудовых коллективов (отноше- } \\
\text { ние заинтересованности): } \\
\text { - применение, по преимуществу, сдельно-преми- } \\
\text { альной системы оплаты труда, в т.ч. за конечные } \\
\text { результаты; } \\
\text { - надбавка механизаторам, работающим на преци- } \\
\text { зионной технике, единовременная доплата за раци- } \\
\text { онализаторские предложения, доплата за качество } \\
\text { работ, доплата за соблюдение технологической } \\
\text { дисциплины } \\
\text { 2. Меры материального стимулирования менедже- } \\
\text { ра технологий (отношение заинтересованности): } \\
\text { установление зависимости переменной части теку- } \\
\text { щей оплаты труда от дохода предприятия в целом, } \\
\text { разовые доплаты за каждое эффективное техноло- } \\
\text { гическое нововведение }\end{array}$ & $\begin{array}{l}\text { Для сельхозпро- } \\
\text { изводителей }\end{array}$ \\
\hline $\begin{array}{l}\text { 4. Необходимо разработать } \\
\text { конкретные меры матери- } \\
\text { альной ответственности } \\
\text { коллективов подразделе- } \\
\text { ний крупных предприятий } \\
\text { и работников за результаты } \\
\text { управления технологиями }\end{array}$ & $\begin{array}{l}\text { Меры технологической ответственности по уров- } \\
\text { ням (ступеням) управления: } \\
\text { а) для внутрипроизводственных подразделений, } \\
\text { управляемых административно или применяющих } \\
\text { лишь отдельные элементы хозрасчета, целесоо- } \\
\text { бразно устанавливать жесткие меры ответствен- } \\
\text { ности за точное соблюдение технологических } \\
\text { параметров; б) в отношении структурных под- } \\
\text { разделений, работающих на основе углубленного } \\
\text { внутрихозяйственного хозрасчета, - более мягкие } \\
\text { меры, например, за соблюдение принятых техноло- } \\
\text { гий в принципе с возможностью самостоятельного } \\
\text { введения совершенствующих инноваций без ради- } \\
\text { кальных изменений; в) в то же время для подразде- } \\
\text { лений предпринимательского типа - применять от- } \\
\text { ветственность по ряду контрольных показателей, } \\
\text { определяющих дальнейшее устойчивое развитие } \\
\text { предприятия (показатели, характеризующие пло-- } \\
\text { дородие почвы, экологическую обстановку, инно- } \\
\text { вационный и технический потенциалы и т.п.). }\end{array}$ & $\begin{array}{l}\text { Для крупных } \\
\text { предприятий (от- } \\
\text { дельные элемен- } \\
\text { ты - для средний } \\
\text { и малых предпри- } \\
\text { ятий) }\end{array}$ \\
\hline
\end{tabular}




\section{Библиографический список}

1. Губанов С.С. Державный прорыв. Неоиндустриализация России и вертикальная интеграция. Серия «Сверхдержава». - М.: Книжный мир, 2012.

2. Новиков А.И. Особенности формирования трудовых отношений в России в свете задач неоиндустриального развития // Ученые записки. - 2017. - №1 (21). - С. 20-24.

3. Рожкова Н.К. Учет затрат методом «Директ-костинг»// Вестник университета. - 2012. № 3. - URL: https: //cyberleninka/ru/article/v/uchet-zatrat-metodom-direct-kosting (дата обращения: 06.11.2018).

4. Коновалова Л.К., Конищева Е.Н. Система управления технологиями как экономическая категория // Современные наукоемкие технологии. Региональное приложение. - 2015. - №2 (42). - С. 22-28.

5. Гарина Е.П. Государственное субсидирование сельского хозяйства в условиях вступления в ВТО // Аэкономика. - 2014. - № 2 (2).

6. Кирюшин В.И. Экологизация земледелия и технологическая политика. - М.: Изд-во МСХА, 2000. -473 c.

7. Министерство Российской Федерации. Приказ от 6 июля 2017 года № 325 «Об утверждении Методики расчета показателя почвенного плодородия в субъекте Российской Федерации [Электронный ресурс]. - URL: mcx.ru 9611670d3210c17d07ba6555c5c17.pdf (дата обращения 21.01.2018).

8. Арутюнян Ф.Г. Концептуальные аспекты организации экономического стимулирования сельскохозяйственного производства // Экономика сельскохозяйственных и перерабатывающих предприятий. -2016. - № 3. - С. 58-62.

9. Коновалова Л.К., Ильин Л.И. Ответственность за соблюдение технологических и агроэкологических требований в процессе управления технологиями // Владимирский земледелец. - 2017. № 4 (82). - С. 2-6.

10. Трудовой Кодекс РФ. - М.: «Проспект», 2007. - 206 с. 